\title{
Case study: using participatory photographic methods for the prevention of medication errors
}

\author{
Relato de caso: o uso de metodologias fotográficas participativas para a prevenção de erros de medicação
} Estudio de caso: utilización de métodos fotográficos participativos para la prevención de errores de medicación

\section{Ana Paula Gobbo Motta', Juliana Magalhães Guerreiro', Ana Flora Fogaça Gobbo", Luciana Kusumota', Elisabeth Atila'", Rebecca O. Shasanmiv ${ }^{\text {IV }}$ Fernanda Raphael Escobar Gimenes' \\ 'Universidade de São Paulo, Ribeirão Preto College of Nursing. Ribeirão Preto, São Paulo, Brazil. \\ "Módulo University Center. Caraguatatuba, São Paulo, Brazil. \\ "I' Mona Vale District Hospital. New South Wales, Australia. \\ iv Nursing and Public Health Researcher. Philadelphia, United States of America.}

How to cite this article:

Motta APG, Guerreiro JM, Gobbo AFF, Kusumota L, Atila E, Shasanmi RO, Gimenes FRE.

Case study: using participatory photographic methods for the prevention of medication errors.

Rev Bras Enferm [Internet]. 2018;71(5):2483-8. DOI: http://dx.doi.org/10.1590/0034-7167-2017-0040

Submission: $03-16-2017$

Approval: 01-27-2018

\section{ABSTRACT}

Objective: To describe the experience of using participatory photographic research methods to engage nurses and researchers in a collaborative study to improve medication safety conditions, particularly in patients with feeding tubes in a nursing home for the elderly (NHE). Method: This qualitative study was conducted in Brazil and proceeded in iterative phases of visual and textual data collection and analysis. Interviews, subsequent nurse-led photo-narrated walkabouts, and photo elicitation were used with nurses. Results: The need to transform the work design and the workplace to improve medication safety and improving medication processes through effective communication was identified. Unsafe workforce is a challenge in achieving safe medication administration practices; and lack of a patient safety culture is a barrier for adaptive learning and growth. Conclusion: Our findings demonstrated the effectiveness of a restorative research approach for supporting nurses to study and act on medication safety.

Descriptors: Medication Errors; Aged; Photography; Interviews; Qualitative Analysis.

\section{RESUMO}

Objetivo: Descrever a experiência do uso de metodologias de pesquisa fotográfica participativa para envolver enfermeiros e pesquisadores em um estudo colaborativo para melhorar as condições de segurança de medicação, especialmente em pacientes que recebem alimentação enteral em uma Instituição de Longa Permanência para Idosos (ILPI). Método: Esta pesquisa qualitativa foi desenvolvida no Brasil, seguindo fases iterativas de coleta de dados visuais e textuais e análise. Entrevistas, encontros informais com narração fotográfica conduzida pelos enfermeiros, e evocação de fotografias foram utilizados com os participantes. Resultados: A necessidade de transformar o formato e o local de trabalho para melhorar a segurança e os processos de medicação através de uma comunicação efetiva foi observada. Uma força de trabalho sem segurança é um desafio para alcançar práticas seguras de administração de medicação; e a falta de uma cultura de segurança do paciente é uma barreira para a aprendizagem adaptativa e o crescimento. Conclusão: Nossos achados demonstraram a efetividade de uma abordagem de pesquisa restaurativa para ajudar enfermeiros a estudarem e agirem a favor da segurança da medicação.

Descritores: Erros de Medicação; Idoso; Fotografia; Entrevistas; Análise Qualitativa.

\section{RESUMEN}

Objetivo: Describir utilización de métodos participativos de investigación fotográfica para involucrar enfermeras e investigadores en estudio colaborativo para mejorar condiciones de seguridad de medicación, particularmente en pacientes con sondas alimentarias en asilo para ancianos (NHE). Método: Estudio cualitativo realizado en Brasil, desarrollado en fases iterativas de recolección y análisis de datos visuales y textuales. Se utilizaron entrevistas, caminatas fotográficas dirigidas por enfermeras, y obtención de fotografías con ellas. Resultados: Fue identificada la necesidad de transformar diseño de trabajo y ámbito laboral para mejorar seguridad y procesos de medicación mediante una comunicación efectiva. La mano de obra insegura constituye un desafío para obtener prácticas seguras de administración de medicamentos; la falta de cultura de seguridad del paciente dificulta el aprendizaje adaptativo y el crecimiento. 
Conclusión: Nuestros hallazgos demostraron la efectividad de un enfoque restaurador de investigación para apoyar a las enfermeras a estudiar y actuar sobre seguridad de la medicación.

Descriptores: Errores de Medicación; Anciano; Fotografía; Entrevistas; Análisis Cualitativo.

\section{CORRESPONDING AUTHOR}

Ana Paula Gobbo Motta

E-mail: ana.paula.motta@usp.br

\section{INTRODUCTION}

Statistical projections show that the number of elderly Brazilians will increase by 15 times between 1950 and 2025. Since the beginning of the $20^{\text {th }}$ century, Brazilians have been living longer and have undergone changes to their epidemiological profile $^{(1)}$, which is related to the increasing demands for providing food and medications via feeding tubes. However, elderly patients undergoing treatment with feeding tubes are vulnerable to adverse events, and nursing guidelines focusing on handling of these tubes are not always based on scientific evidence but rather on the rituals and opinions of specialists ${ }^{(2)}$.

Administering medications through feeding tubes is a common nursing procedure used in a variety of settings. Feeding tubes are frequently associated with adverse drug events, particularly in older people, because a significant number of medications prescribed in nursing homes for the elderly (NHE) are considered inappropriate for this route. Most studies focus on hospitalized patients in acute care settings, yet a significant number of elderly patients who use feeding tubes are in NHEs. Therefore, studies in NHE are necessary to address this discrepancy.

\section{OBJECTIVE}

To describe the experience of using participatory photographic research methods from the field of ecological restoration to engage nurses and researchers in a collaborative study. The central research question: could restorative photographic research methods help Brazilian nurses to (re)think and improve their approach to medication safety through feeding tubes in their work environment?

\section{METHOD}

\section{Ethical aspects}

The research was approved by the Research Ethics Committee of the University of São Paulo at Ribeirão Preto College of Nursing. The guidelines of the Brazilian National Research Council were followed, participants were assured that their identity would remain confidential, and the written consent form stipulated that they could decline or withdraw from the research at any time with no repercussions in their work.

\section{Type of study}

This is a qualitative study used a participatory photographic research methods from the field of ecological restoration.

\section{Methodological procedures}

Each participant received explanations of the research before signing voluntary consent forms. A selection of participatory photographic research methods adapted from the field of ecological restoration ${ }^{(3)}$ and from a previous study ${ }^{(4)}$ were used, including interviews and subsequent nurse-led photo-narrated walkabouts of the nursing home, followed by photo elicitation with nurses. The research proceeded in iterative phases of visual and textual data collection and analysis conducted in four phases.

\section{Study scenario}

This study was conducted in a NHE in the state of São Paulo in Brazil from January 2014 to May 2015. Eight healthcare professionals were working in that location at the time of data collection: one registered nurse, four nurse auxiliaries, one nurse technician, and two elderly caregivers. The elderly caregivers were excluded from the study, because only registered nurses, nurse technicians, and nurse auxiliaries are allowed to administer medications in Brazil. Participants were invited to engage in the research and initial contact was made through the nurse manager, who approached the NHE team on the researchers' behalf. One registered nurse, one nurse technician, and two nurse auxiliaries agreed to participate; their ages ranged from 36 to 50 years, and they had been working at the nursing home between two to eight years.

\section{Stages of work}

In phase 1, participant interviews were conducted with the aim of determining the current practices of medication preparation and administration through feeding tubes. The audiotaped data from interviews were transcribed verbatim and were analyzed using inductive content analysis. Based on this analysis, a list of issues relating to medication management through feeding tubes was developed for use in the second phase.

In phase 2, researchers used the findings from Phase 1 as a starting point to conduct two sessions of tape-recorded photo walkabouts with an experienced nurse to capture and narrate photos of the NHE and the processes of medication preparation and administration. The researchers coded the Phase 2 photographs and narrative text to identify relevant risks to medication safety in the nursing home, and then compared their initial analyses to derive preliminary themes.

In phase 3, photo elicitation was conducted with nurses of unit photographs and preliminary narrative themes, with the aim of eliciting their views of the relevant phenomena. Nurses viewed the photographs and shared their perceptions and stories of medication administration via feeding tubes. For data analysis, the same procedures as before were utilized. Whilst talking about the images, nurses would be able to envision a safer place in which to provide care.

In phase 4, three months after photo elicitations, researchers returned to the NHE to verify, through direct observation, and to register, through photographs, changes in the work environment in response to the interviews and photo walkabout/photo narration. The final themes were developed by consensus, to assure rigor, from joint discussions by the research team and study participants. 


\section{RESULTS}

Participants identified several aspects of their work environment that pose threats to adverse drug events through feeding tubes in the NHE. The iterative data analysis derived four major themes, and the selected findings are presented for each theme to illustrate our understanding of the issues explored.

\section{Transforming the work design and the workplace to improve medication safety}

In terms of the nursing station design, some aspects were considered potential risks to medication safety. The door to the nursing station remained open, facilitating access by anyone, including the elderly patients. There was also a broken lock on one of the medicine cabinets in the nursing station.

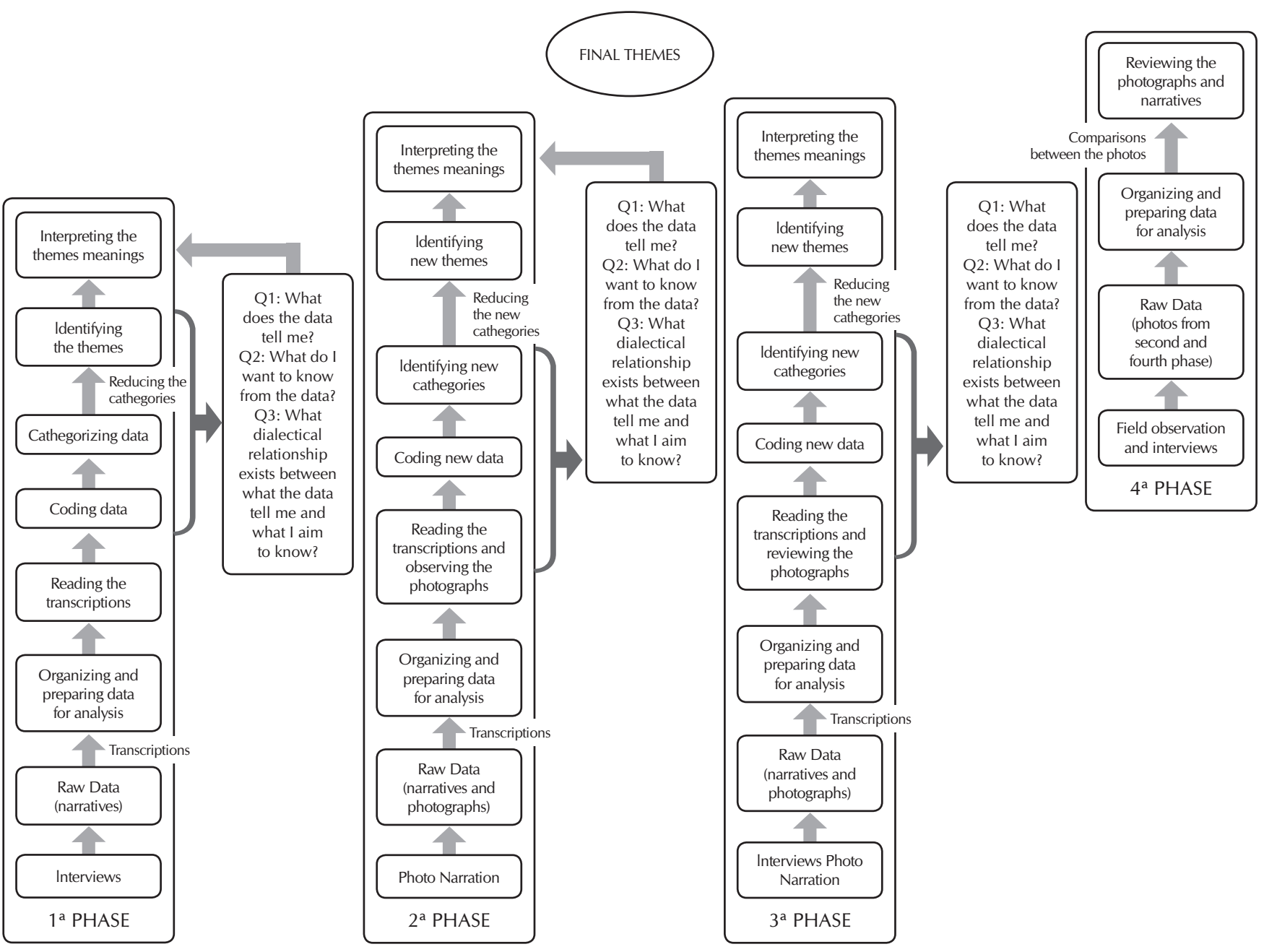

Source: Adapted from Gimenes \& Cassiani, 2013(4)

Figure 1 - Collection and interactive analysis of the data, according to restorative research
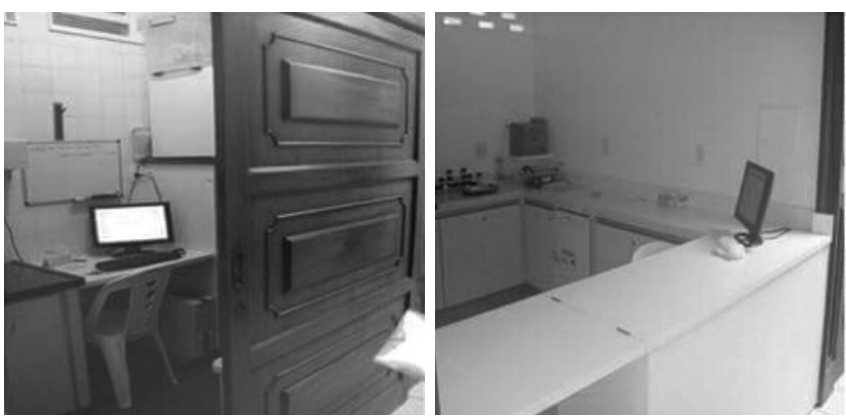

Figure 2 - Nursing station design, before and after research
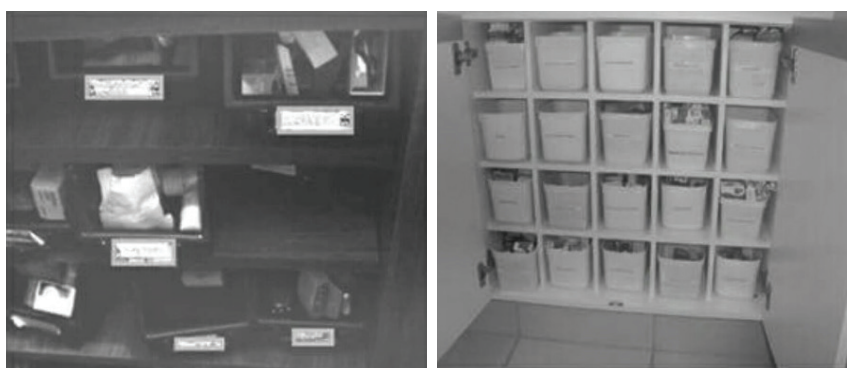

Figure 3 - Organization and identification of niches, before and after the study 
[...] It's a mistake, I couldn't agree more, this door should be closed, but this door has no key. Because it is a very old lock, it is difficult to adjust the lock on the door with that on the wall. (P.1)

The nursing station had several changes made, including the installation of new cabinets, and replacement of locks and keys on preexisting cabinets that contain medications. After the changes, this minimized the movement of people inside the nursing station (Figure 2).

The accessibility of supplies and medications during emergencies was another concern to nurses. Before the study, the nurses had trouble finding materials and, for this reason, they decided to create an emergency kit with contents to streamline care:

[...] There is the box that we prepared for urgent care. Because [if] the patient crashes suddenly [...] then I and [another nurse], we say 'take this, take that', so here we have it all. (P.2)

Before the study, psychotropic medications were stored in an unlocked closet in the office with access restricted to the team leaders of the NHE, to the nursing technician, and to the cleaner. According to one participant:

$[\ldots .$. It is in the office [...] but there is an employee who does a weekly cleaning of this location. (P.2)

After the changes, psychotropic medications were stored in a locked cabinet in the nursing station, and the key kept by the nurse. However, the cabinet where materials and other medications were stored remained unlocked, facilitating easy access by residents. The participant below reiterated the problem:

It [the cabinet] is leaning, but not closed [...] It had a lock, but it broke. (P.4)

Participants expressed concern about how the staff organize their work, including routines and workflow. The niches with medications were in a cabinet at the nurses' station, but arranged according to employee preference, as demonstrated in the following participant statement:

[...] There is no first name and last name, there is only the first name, which is exactly how they [nursing team] know the patients, how the patients like to be called is the way that they are identified [...]. (P.3)

Employees were willing to modify their workplace to promote the safety of the residents of the NHE.

\section{Improving medication processes through effective communication}

According to participants, electronic prescriptions improved workplace communication between physicians and nurses because when prescriptions are checked, they change color. E-prescriptions helped reduce the occurrence of incidents with medications related to illegibility. The electronic system encouraged communication between the nurses, because the system signals whether the medication was administered or not:
Electronic prescribing is here [...] here are the drugs that have already been checked, and here in blue are the drugs that have not yet been checked [...] So, I am able to have control of all the drugs that were administered. (P. 3)

Participants agreed that easy access to information about drugs improves communication among the healthcare team. Facilitative measures identified by the participants in the communication process were sources of information available about medicines (internet and books) and the existence of clinical protocols.

The protocols available at the NHE did not include the preparation and administration of medicines via feeding tubes. Before the study, the Dictionary of Administration of Medicines was kept in the office, and was unknown to some nurses. In the fourth phase of the study, the dictionary was accessible in the nurses' station.

\section{Unsafe workforce is a challenge for sound practices relating to medication administration}

According to participants, nurses lack sufficient training to improve safety of administering medications via feeding tubes in the NHE. The participants recognized the incorrect techniques used in the preparation and administration of medicines. A participant commented:

[...] everyone prepares [the medicines] in their own way [...]. (P.2)

In Phase 2, the following errors were observed during preparation and administration of oral medications via feeding tubes: grinding of various drugs in a single container; failure to check placement of the tube before administering the medication(s); and failure to flush the tube after administration. These errors resulted in incidents and consumed most of the nurses' time. One participant commented:

[...] There are some medicines that clog [the feeding tube] a lot. You end up clogging the tube, you waste your time, you have to redo it, have to wash the tube, it is a big job. (P.1)

There are no protocols or regular training programs for nurses aimed at best practices in the preparation and administration of medications via feeding tubes at the institution. According to the participants, training occurs sporadically, and only when there are specific questions about a particular procedure. On these occasions, the nurse provides verbal guidance to the other professionals.

\section{Lack of a patient safety culture is a barrier for adaptive learning and growth}

Participants' fear of speaking openly about the incidents was observed, due to the policy of verbal and written warnings when adverse events occurred, demonstrating the culture of punitive action in the institution. According to the participants, the NHE had a system of voluntary - but not anonymous - notification of adverse events, since the professional needs to access the system to register a notification: 
[...] because I've had colleagues who said they did not register the event because they were afraid [...]. (P.2)

For the participants, a change in the culture of punishment would improve communication among all the professionals involved and, consequently, quality of care.

\section{DISCUSSION}

Our findings demonstrated the effectiveness of a restorative research approach for supporting nurses of an NHE to study and act on a number of medication safety issues within the study setting. In phase 1, nurses recognized sound practices and diagnosed a variety of risks to medication safety within their work environment and medication system. The second phase participant-led photo walkabouts heightened nurses' awareness of problematic issues, but also fostered their ability to openly discuss safety concerns and begin to explore possibilities for change. The third phase of the photo elicitation process opened up dialogue amongst the researchers and nurses which reinforced the idea that change was possible and desirable to promote a safer work environment, and mobilized nurses to work together to achieve these goals.

Restorative health research emphasizes the dynamics of the processes and behaviors in interactions between individuals and the places where they live and work, because there is a relationship between personal characteristics and those found in the environment. This theoretical perspective is used to study complex relations between the healthcare system and the social arrangements of people who provide or receive care ${ }^{(5)}$.

The use of feeding tubes for administering food and medications to elderly people living in NHE is a practical problem, as these patients are often discharged from hospital with feeding tubes insitu. This type of intervention has increased, but there are few studies on the use and handling of this device in elderly patients ${ }^{(6)}$.

The NHE in this study provided care to elderly patients using feeding tubes, but there are no clinical protocols or standardization of nursing care for this intervention, which increases the risk of adverse events.

Some guidelines for the safe handling of feeding tubes ${ }^{(7)}$ include: 1) Check the availability and compatibility of pharmaceuticals in liquid form. 2) Verify that the prescribed drugs are compatible with crushing and administering via feeding tubes. 3) Crush solid medications separately into fine, homogeneous powder. 4) Check the correct positioning of the tube before administering medications. 5) Do not add medications to feeding formula. 6) Before administering medications, stop the nutritional feeding and flush the tubes with 15 to $30 \mathrm{ml}$ of water before and after drug administration, considering patient's fluid balance and age. 7) If necessary, stop the nutritional feeding for a given time period; this should be restarted as soon as possible, and the interruption should be communicated to the nutrition team, so that the patient's nutritional intake is not compromised. 8) Institute preventive barriers, such as the identification of medicines that should not be crushed. 9) Implement regular nutritional feeding education programs and encourage interdisciplinary work among physicians, pharmacists, nutritionists and nursing staff, aiming to promote patient safety.
Polypharmacy, common in the elderly population, is a term used to designate the use of multiple medications. The prevalence of polypharmacy in elderly patients varies from $20 \%$ to $40 \%$, and increases the complexity of clinical management, contributing to adverse reactions to medicines. Adverse drug/drug and drug/ nutrient interactions when administrating medications via feeding tubes should be avoided. One of the best pharmaceutical strategies recommended to minimize risk and achieve better practices for polypharmacy is the appropriate prescription of multiple medications, which is dependent on professional skill and knowledge ${ }^{(8)}$.

The confirmation of the location of the tube before medication administration helps to prevent aspiration pneumonia. The occurrence of this condition in elderly residents in NHEs is relevant due to its negative clinical consequences. Conversely, low incidences of aspiration pneumonia is related to adequate nursing care provided to patients using long-term feeding tubes ${ }^{(9)}$.

Restorative health research is a new approach, in which the environment and study participants support the findings to understand the phenomenon and act on it. This methodology allows participants to indicate problems, and researchers act as facilitators for the perception of such events. Organization of the environment is an important factor that contributes to improving patient safety. This is especially valid for elderly patients with dementia, who are present in large numbers in NHEs, because they have specific needs for their living spaces in order to achieve the best results of treatment ${ }^{(10)}$. In the present study, the nursing professionals realized that the nursing station environment needed change to facilitate patient safety in the NHE.

\section{Limitations of the study}

The sampling of nursing staff is a limitation on these findings, since it is a study in an NHE with a limited number of participants from the same discipline. It is not possible to say whether the changes in the environment and processes will minimize errors in administering medications via feeding tubes, since there was no examination of errors before and after the study.

\section{Contributions to the area of nursing and public health}

The process of taking pictures, narrating the context of the photos, and presenting them, created an ongoing discussion regarding the need to change and promote a safer environment for medication management. The research methods used empowered nurses to address medication safety by promoting advocacy that leads to policy changes.

\section{CONCLUSION}

The restorative research approach engaged nurses in the re-examination of their practices and their environment as the research progressed. Restorative methods suggest the potential merits of healthcare institutions adopting more participatory forms of management where frontline professionals and organizational leaders are encouraged to collectively build shared knowledge of the weaknesses and strengths in their complex care environments. If people can learn how to use restorative methods to increase dialogue and transparency about their current practices and workplace conditions, perhaps they can also use the research 
methods to re-imagine and achieve safer, more effective systems of care. To pursue that hypothesis, it will be important in future restorative research to measure the sustainability of patient safety intervention outcomes over time to assess the cost-benefits of the adoption of such management models.

\section{FUNDING}

The authors wish to thank the University of São Paulo ProRectory of Research and the National Council of Technological and Scientific Development (CNPq) for the budget.

\section{REFERENCES}

1. World Health Organization-WHO. World report on ageing and health [Internet]. Geneva: World Health Organization; 2015. [cited 2017 Jan 20]. 260 p. Available from: http://apps.who.int/iris/bitstream/10665/186463/1/9789240694811_eng.pdf

2. Simons SR, Abdallah LM. Bedside assessment of enteral tube placement: aligning practice with evidence. Am J Nurs[Internet]. 2012[cited 2017 Jan 20];112(2):40-6. Available from: https://www.ncbi.nlm.nih.gov/pubmed/22261653

3. Marck PB, Kwan JA, Preville B, Reynes M, Morgan-Eckley W, Versluys R, et al. Building safer systems by ecological design: using restoration science to develop a medication safety intervention. Qual Saf Health Care[Internet]. 2006[cited 2017 Dec 17];15(2):927. Available from: https://www.ncbi.nlm.nih.gov/pubmed/16585107

4. Gimenes FRE, Cassiani SHDB. Safety in medication preparation and administration, in light of restorative health care research. Rev Min Enferm[Internet]. 2013[cited 2017 Dec 20];17(4):966-74. Available from: http://www.reme.org.br/artigo/detalhes/899

5. Parke B, Hunter KF, Marck PB. A novel visual method for studying complex health transitions for older people living with dementia. Int J Qual Meth[Internet]. 2015[cited 2017 Dec 20];14(4):1-11. Available from: http://journals.sagepub.com/doi/ full/10.1177/1609406915614150

6. Serrano Santos JM, Poland F, Wright D, Longmore T. Medicines administration for residents with dysphagia in care homes: a small scale observational study to improve practice. Int J Pharm[Internet]. 2016[cited 2017 Dec 20];512(2):416-21. Available from: https://www.ncbi.nlm.nih.gov/pubmed/26906457

7. Instituto para Práticas Seguras no Uso de Medicamentos. Preparo e administração de medicamentos via sonda enteral ou ostomias. Belo Horizonte: Boletim ISMP Brasil[Internet]. 2015[cited 2017 Jan 16]. 5 p. Available from: http://www.ismp-brasil.org/site/wpcontent/uploads/2016/03/Boletim-sondas.pdf

8. Hughes CM, Cadogan CA, Patton D, Ryan CA. Pharmaceutical strategies towards optimising polypharmacy in older people. Int J Pharm[Internet]. 2016[cited 2017 Jan 20];512(2):360-5. Available from: https://www.ncbi.nlm.nih.gov/pubmed/26921516

9. Gorzoni ML, Faria LFC, Brandão A, Carmo Fd, Valente M, Pires SL. Sondas de alimentação e broncopneumonias aspirativas. Arquivos Médicos dos Hospitais e da Faculdade de Ciências Médicas da Santa Casa de São Paulo[Internet]. 2013 [cited 2017 Jan 20];58:24-8. Available from: http://arquivosmedicos.fcmsantacasasp.edu.br/index.php/AMSCSP/article/view/216/228

10. Parke B, Hunter KF, Strain LA, Marck PB, Waugh EH, McClelland AJ. Facilitators and barriers to safe emergency department transitions for community dwelling older people with dementia and their caregivers: a social ecological study. Int J Nurs Stud[Internet]. 2013[cited 2017 Jan 18];50(9):1206-18 Available from: https://www.ncbi.nlm.nih.gov/pubmed/23219329 